\title{
El turismo comunitario urbano como forma de re- existencia cultural y laboral. El modelo de Barrio Egipto (Bogotá)
}

\section{Community Based Tourism in Slum as a form of cultural and labor re-existence. The Barrio Egipto model (Bogotá)}

\author{
Simone Ferrari \\ simone.ferrari1@unimi.it \\ Università degli Studi di Milano, Italia / \\ Pontificia Universidad Javeriana de Bogotá, \\ Colombia
}

\section{Recepción: 30 Junio 2020}

Aprobación: 27 Noviembre 2020

Publicación: 01 Febrero 2021

Cita sugerida: Ferrari , S. (2021). El turismo comunitario urbano como forma de re-existencia cultural y laboral. El modelo de Barrio Egipto (Bogotá). Cuestiones de Sociología, 24, e115. https://doi.org/10.24215/23468904e115
Resumen: La expansión de las metrópolis en América Latina se ha realizado a partir de matrices de exclusión sociocultural de las localidades urbanas informales, o "geografías violentadas" (Jaramillo Marín, Parrado Pardo y Louidor, 2019), caracterizadas por condiciones de abandono institucional, desarticulación social y normalización de la violencia. Ante dichos procesos de marginación, pueden surgir desde los espacios barriales estructuras autónomas y comunitarias dirigidas a constituir posibilidades laborales alternativas. Es el caso de la iniciativa de turismo comunitario Breaking Borders del Barrio Egipto Alto de Bogotá. El presente ensayo pretende abordar un análisis del proyecto a partir de la noción de "re-existencia" (Gonçalves de Lima, 2005), aplicada a los ámbitos cultural y laboral, para profundizar los patrones que caracterizan la construcción comunitaria y autónoma de la experiencia turística: el arte visual y la memoria oral. El marco metodológico de la investigación ha incorporado un trabajo de campo (participación en tours y entrevistas a miembros del proyecto y habitantes del barrio realizadas entre 2018 y 2020) y una profundización bibliográfica de la noción de turismo comunitario, dentro de un estudio comparado apto para colocar el modelo de Barrio Egipto en una mirada continental.

Palabras clave: Turismo comunitario, Geografías violentadas, Re-existencia, Barrio Egipto.

Abstract: The expansion of metropolises in Latin America has been carried out through sociocultural exclusion of informal urban localities, or "Geographies of Violence" (Jaramillo Marín, Parrado Pardo y Louidor, 2019), characterized by conditions of institutional abandonment, social disarticulation and normalization of violence. In the face of these processes of marginalization, autonomous and community structures may emerge, aimed at constituting alternative employment opportunities. This is the case of the Breaking Borders community tourism initiative in the Egipto Alto district in Bogotá. The present essay points to approach an analysis of the project starting from notion of "re-existence" (Gonçalves de Lima, 2005), applied to the cultural and labor fields, to deepen the patterns that 
characterize the community and autonomous construction of the experience of tourism: visual art and oral memory. The methodological setting of the research has incorporated field work, with observation of various tours and interviews with project organizing members and inhabitants of the neighborhood carried out between 2018 and 2020, and a bibliographic study of the notion of community based tourism, within the framework of a comparative study in a continental perspective.

Keywords: Community Based Tourism, Geographies of Violence, Re-Existence, Barrio Egipto.

\section{El turismo comunitario urbano como forma de re-existencia cultural y laboral. El modelo de Barrio Egipto (Bogotá)}

El presente artículo plantea un análisis de los mecanismos constitutivos y de los impactos en el territorio de la experiencia de turismo comunitario urbano Breaking Borders, impulsada desde la homónima organización barrial activa en la Calle 10 del Barrio Egipto Alto, ubicado en los cerros orientales del Distrito Capital de Bogotá (Colombia).

En primer lugar, se presentarán las nociones de "geografías violentadas" y "re-existencia", en el marco de una dicotomía propia de los procesos de exclusión sociocultural sobre los cuales se funda el desarrollo de las metrópolis latinoamericanas. Seguidamente, se posicionará el proyecto Breaking Borders en el marco teórico de los estudios acerca del turismo comunitario y en el conflictivo contexto socio-histórico de Barrio Egipto Alto.

A partir del enfoque teórico desarrollado, y con la contribución de algunas entrevistas realizadas a miembros del proyecto y habitantes del barrio, se analizarán los elementos culturales propios del proceso de conformación de la experiencia turística: la gestión autónoma y colectiva del proyecto, el uso del arte visual en tanto proceso de activación de íconos de re-existencia y la inclusividad comunitaria en la construcción de las memorias orales propuestas a los turistas. Finalmente, se plantearán unos apuntes acerca de las posibilidades y problematicidades de la exportación del modelo de Barrio Egipto a otros contextos latinoamericanos.

\section{Introducción: marginación y re-existencia en las periferias urbanas latinoamericanas}

La expansión masiva de las metrópolis en América Latina en la segunda mitad del siglo XX no tiene como único factor dinamizador la migración del campo a la ciudad. Los procesos de desplazamiento masivo hacia los espacios urbanos se han intensificado a partir de la centralización del papel de las ciudades en tanto fuerzas productivas (Pérez Zamorano, 2010). Esta dislocación se ha realizado a partir de políticas de exclusión de cuerpos y territorios, progresivamente marginados por medio de formas de confinamiento propias de las prácticas de desarrollo urbano impulsadas por el sistema neoliberal. Tal y como lo plantea el geógrafo David Harvey, 
La urbanización concentra espacialmente las fuerzas productivas, así como la fuerza de trabajo, transformando las poblaciones dispersas y los sistemas de derechos sobre la propiedad descentralizados en masivas concentraciones de poder político y económico que finalmente se consolidan en el aparato jurídico militar del Estadonación. (Harvey, 2003, p. 39).

En las metrópolis continentales, las dinámicas de concentración poblacional del espacio urbano han ocasionado una marginación estructurada de los sectores informales, considerados como excedentes de los centros productivos e imaginados como "mundos aislados" (Saraví, 2008, p. 93). Estos procesos de gentrificación y jerarquización urbana no aparecen como evoluciones naturales de un proceso ínsito al crecimiento de la ciudad: más bien, como lo señala Ramiro Segura, para la consolidación de las disparidades "es clave un conjunto de vehículos sociales y políticos” (Segura, 2014, p. 24). En América Latina, estas dinámicas se han alimentado por medio de políticas de exclusión basadas en "la higienización social y la modernización selectiva del territorio" (Janoschka y Sequera, 2014, p. 18); es decir, en mecanismos de desalojo y explotación de aquellos sectores urbanos no englobados en el sistema neoliberal.

El desequilibrio social propio de la evolución urbana es definido por Gabriel Horacio Álvarez, en su estudio sobre la extensión del Área Metropolitana de Buenos Aires, como "una sucesión de olas expansivas desiguales del desarrollo capitalista" (Álvarez, 2005). A pesar de las diferenciaciones en las implicaciones sociales de los procesos de exclusión que distinguen las metrópolis de América Latina, los fenómenos de segregación urbana operan en el marco de trayectorias político-económicas de escala continental.

Entre las tendencias que matizan las formas de desarrollo de la ciudad latinoamericana en la contemporaneidad es posible identificar una noción del espacio fundada en la perspectiva de una jerarquía territorial, donde los epicentros económicos se imaginan en tanto lugares apropiados "para la acumulación de riqueza y la extracción de mercancías” (Torres Tovar y Rincón García, 2011, p. 23), asignándole al suelo funciones preestablecidas a partir de las cuales se estructura el crecimiento urbano.

Este proceso engendra relocalizaciones poblacionales fundadas en la alimentación de desequilibrios económicos y marginaciones de cuerpos; sobre ellos actúan las estructuras de poder a través de estrategias de necropolítica (Mbembe, 2011) entendida aquí como el conjunto de procesos de complicidad e indiferencia estatal hacia la violencia cotidiana, que en estos territorios se expresa en la segregación espacial y en la negación sistemática de los derechos de la ciudadanía (Alves, 2011). Una dinámica gentrificadora socialmente caracterizada por medio de sistemas de subordinación atravesados por "las matrices interseccionales de género, raza, clase y sexualidad" (Bello Ramírez y Parra Gallego, 2016, p. 366): mecanismos que generan ulteriores exclusiones dentro de la marginación.

Dentro de estas matrices continentales, el territorio al cual pretende acercarse este ensayo, el Barrio Egipto Alto de Bogotá, se caracteriza por sufrir un proceso de "fronterización", resultado de modelos de desarrollo que caracterizan la ciudad en tanto "expresión espacial de las diferencias y las desigualdades sociales del país, sintetizadas en los barrios informales” (Torres Tovar y Rincón García, 2011, p. 22). Un proceso de exclusión en el orden social jerarquizado 
de la capital colombiana ejercido a nivel político y trasladado al espacio de los imaginarios urbanos: el progresivo aislamiento sufrido por la población de Egipto Alto y de otros sectores de la ciudad ha impulsado la consolidación de imaginarios colectivos discriminatorios. Las periferias bogotanas han asumido progresivamente el estigma del lugar inaccesible e irrecuperable, tal y como lo señala Franz Fanon al referirse a la ciudad del colonizado:

[...] un Iugar de mala fama, poblado por hombres con mala fama. Allí se nace en cualquier parte, de cualquier manera. Se muere en cualquier parte, de cualquier cosa. Es un mundo sin intervalos, los hombres están unos sobre otros, las casuchas unas sobre otras. La ciudad del colonizado es una ciudad hambrienta, hambrienta de pan, de carne, de zapatos, de carbón, de luz. La ciudad del colonizado es una ciudad agachada, una ciudad de rodillas, una ciudad revolcada en el fango. EI mundo colonizado es un mundo cortado en dos. La línea divisoria, Ia frontera está indicada por los cuarteles y las delegaciones de policía. (Fanon, 1963, pp. 33-34)

Como se argumentará en las siguientes secciones, la "línea divisoria" producida por la radicación de representaciones colectivas que asocian estos barrios a lugares "de mala fama" es alimentada, en el caso de Egipto Alto, por la expansión de fenómenos violentos vinculados con el tráfico y el consumo masivo de droga y con el aumento exponencial de los índices de violencia. Estos mecanismos contribuyen a la colocación del territorio en las matrices estructurales de las "geografías violentadas" (Jaramillo Marín, Parrado Pardo y Louidor, 2019, p. 110); es decir, de las "territorialidades [...] fracturadas, [...] paisajes desarticulados mediante un conjunto de lógicas de violencia directa, de terror expreso y de miedo sistemáticos" (2019, p. 115).

Según la noción planteada por los tres estudiosos colombianos en su aproximación a la ciudad de Buenaventura (Colombia), estos espacios se caracterizan por cierta normalización en la percepción comunitaria de la violencia, por la activación de procesos de brutalización de los cuerpos y de despojo cultural, y por fragmentar las perspectivas de largo alcance de sus habitantes, resignados a un arraigo a la cotidianidad en tanto marco totalizador de la experiencia vital.

Dentro de estas "geografías violentadas" se posibilita el surgimiento de procesos paralelos y complementarios, modelados a raíz de movimientos endógenos aptos para desvincular el territorio del estigma social y del aislamiento económico. En el caso del Barrio Egipto Alto de Bogotá, se han desarrollado de forma autónoma iniciativas conformadas con el objetivo de impulsar la dignificación de la vivencia comunitaria y la generación de producciones culturales y de posibilidades laborales a largo plazo: asociaciones artísticas, talleres musicales y grupos de formación profesional, entre otros. En este marco, se ha engendrado en el territorio una tensión entre "el miedo dirigido y las reexistencias" (Gonçalves de Lima, 2005, p. 83), tal y como lo señala el geógrafo Gonçalves de Lima en relación con la conformación urbana de Río de Janeiro: una fragmentación de los imaginarios entre las fábricas de miedos direccionados hacia ciertas "fronteras invisibles" de las ciudades y, desde las comunidades marginadas, los intentos colectivos de desligarse de dichas representaciones.

En este contexto, me apropio aquí de algunos matices de la noción de re-existencia, en la acepción que le dan Jaramillo Marín, Parrado Pardo y Louidor en relación con las "gramáticas de vida" (Jaramillo Marín, Parrado 
Pardo y Louidor, 2019, p. 118) adoptadas por las comunidades afropacíficas en regiones marcadas por la violencia. La re-existencia se concibe como aquel conjunto de prácticas, iniciativas y vivencias que buscan responder a las desestructuraciones territoriales impulsadas por las geografías violentadas. Ahora bien, si la resistencia urbana en contextos de desigualdades económicas fue concebida por el antropólogo James Scott como un complejo entretejido de procesos cotidianos direccionados a la "creación de un espacio social autónomo para la afirmación de la dignidad" (Scott, 1990), el concepto de re-existencia se mueve en un mismo territorio epistemológico, enfocándose en los objetivos de dichas prácticas: las experiencias incorporadas en esta trayectoria cultural se conforman con el fin de impulsar procesos no violentos y colectivos para "socavar, desafiar, subvertir o burlar desde marcos biográficos, trayectorias organizativas, vivencias barriales, las geografías violentadas" (Jaramillo Marín, Parrado Pardo y Louidor, 2019, p. 118).

Dentro de esta perspectiva es posible posicionar el proyecto Breaking Borders, Rompiendo fronteras, cuya denominación evoca la ambición colectiva de erigir un puente imaginario que posibilite quebrantar las fronteras invisibles que apartan el Barrio Egipto Alto de los centros productivos de la ciudad. Breaking Borders es una iniciativa de turismo comunitario organizada y liderada por algunos habitantes de la Calle 10 del Barrio Egipto Alto de Bogotá: una práctica de reexistencia surgida en 2016, por medio de la cual se ha propiciado la creación de posibilidades laborales autónomas en el sector económico del turismo y de alternativas culturales endógenas a los sistemas de violencia dominantes. Ante la violencia física y simbólica de la segregación urbana, Breaking Borders puede considerarse en primer lugar una de las muchas "estrategias para intentar lidiar con el estigma” (Kessler, 2012, p. 183) que se desarrollan en los barrios subalternos de las metrópolis latinoamericanas. Sin embargo, el proyecto conlleva también procesos de autonomización cultural y social: la iniciativa es gestionada desde los mismos residentes del sector, quienes proponen a los visitantes una experiencia turística basada en narraciones conformadas "desde adentro", constituidas por memorias biográficas, nociones acerca de la historia de la ciudad $\mathrm{y}$ arte visual.

\section{El turismo comunitario como forma de reapropiación de una geografía violentada: el proyecto Breaking Borders (Barrio Egipto Alto, Bogotá)}

En principio, no resulta tan fácil posicionar la iniciativa de re-existencia de Breaking Borders dentro de las variadas aproximaciones teórico-metodológicas acerca de la noción de turismo comunitario y de sus vivencias específicas en distintos contextos de América Latina. El término aparece por primera vez en el textoTourism: A community approach (1985) de Peter Murphy, en el que el turismo comunitario es presentado en el marco de una reflexión acerca de las posibilidades de expansión del mercado turístico hacia las áreas rurales de los países del sur del mundo. En general, la definición abarca cualquier experiencia de turismo organizada mayoritariamente por la población local, que tenga como objetivo el mejoramiento de las condiciones de vida del entorno social y la valoración de los recursos naturales locales (López-Guzmán y Sánchez 
Cañizares, 2009). La caracterización "comunitaria" de la experiencia no remite exclusivamente a los territorios indígenas, sino más bien a una definición de comunidad más transversal en sus manifestaciones geosociales, tal y como lo señala Carlos Maldonado:

[...] lo comunitario designa un sujeto colectivo, con derechos y obligaciones, constituido en base a la adhesión voluntaria de sus miembros (individuos o familias), con o sin sustento institucional en el derecho consuetudinario o en una territorialidad común. La identidad puede nutrirse de un conjunto de objetivos, valores y normas de participación codificados por sus miembros. (Maldonado, 2005, p. 3)

Ahora bien, en América Latina la trayectoria conceptual de la noción de turismo comunitario se asocia, desde su comienzo, a regiones no-urbanas, y se vincula por lo general a proyectos ubicados en territorios indígenas y campesinos. Es el caso de los estudios acerca de experiencias de turismo comunitario de la región de Cusco en Perú (Casas Jurado, Soler Domingo y Pastor, 2012), de algunas áreas rurales de Costa Rica (Trejos y Matarrita-Cascante, 2010), de la Ruta de las Flores en El Salvador (López-Guzmán Guzmán y Sánchez Cañizares, 2009), de las regiones indígenas del Ecuador (Ruiz et al., 2008), del municipio amazónico de Silves (Brasil) (Gruber Sansolo, 2003), entre otros.

Además del posicionamiento en espacios rurales, en el heterogéneo conjunto de estudios acerca de teorías, métodos y prácticas de turismo comunitario en América Latina se destacan algunos caracteres comunes, que nos permiten definir la dimensión sociocultural de estos proyectos: la centralización de la sustentabilidad ecológica, la preservación de los recursos naturales y la valoración de la identidad étnica de las comunidades y de los territorios de referencia (Orgaz Agüera, 2013). Básicamente, estos proyectos suelen colocarse en las extremidades de los siguientes ejes conceptuales duales, propios del análisis de las dinámicas turísticas: turismo alternativo-turismo de masa (Orgaz Agüera, 2013) y turismo rural-turismo urbano (Parker y Romero, 2015).

$\mathrm{Si}$ bien las iniciativas comunitarias acostumbran caracterizarse por ser alternativas al turismo de masa y ubicadas en espacios rurales, en época reciente se han impulsado tendencias desemejantes. Es el caso del turismo indígena urbano de Santiago de Chile (Parker y Moreno, 2015) o de los "turismos de favela” en Río de Janeiro (Rodrigues da Silva et al., 2014) y en Medellín (López Zapata, Mees y Gómez, 2017). Este último modelo, además de posicionarse en un espacio metropolitano, es considerado por algunos estudiosos como expresión de los flujos turísticos de masa, en tanto experiencias que expropian la cultura autónoma y mercantilizan las vivencias comunitarias (Machado, 2007), particularmente en los casos en los que no son efectivamente controlados por la población local (Frisch, 2012).

A pesar de las problematizaciones señaladas, este tipo de proyectos en los espacios periféricos urbanos puede actuar de forma contundente y directa en la construcción de posibilidades laborales y de mejoría de las condiciones sociales del territorio. En el caso de Breaking Borders, este elemento se conjuga con una progresiva elaboración de formas narrativas de autorrepresentación, orales $\mathrm{y}$ visuales, las cuales intervienen directamente en el territorio en tanto procesos dinamizadores de una transformación social autónoma. El sistema de autogestión por medio de la cual Breaking Borders organiza modalidades, participación y 
tiempos de su experiencia turística da cuenta de un caso único, en el contexto del turismo comunitario urbano, por su desvinculación absoluta de corporaciones o instituciones estatales y privadas.

En los siguientes párrafos, después de esbozar una presentación contextual de las condiciones territoriales del Barrio Egipto, se definen las matrices centrales del proyecto a partir de tres ejes dominantes: el arte visual, las memorias orales y la inclusividad. Historia y características de la iniciativa Breaking Borders se han analizado por medio de un trabajo de campo comenzado en julio de 2018 y terminado en febrero de 2020. El trabajo de campo ha consistido de dos momentos principales: la observación participante durante más de veinte tours realizados entre julio de 2018 y febrero de 2020 (i), y las entrevistas realizadas a los dos fundadores del proyecto, a dos guías y a tres habitantes del sector entre noviembre de 2018 y octubre de 2019 (ii). Todos los entrevistados nacieron entre finales de los años sesenta y comienzos de los años ochenta; es decir, vivieron en primera persona los años más cruentos de la violencia barrial (1990-2002).

\section{Antecedentes históricos: condiciones territoriales y violencia estructural}

La organización Breaking Borders surgió en julio de 2016 en tanto iniciativa autónoma e independiente de macroproyectos turísticos, liderada por dos habitantes del barrio y coordinada con la colaboración de más de veinte guías turísticos, todos residentes en el sector. Como se argumentará a lo largo de la sección, si bien la iniciativa se concibió y se mantuvo hasta la actualidad en modalidad de autogestión social y territorial, en su desarrollo asumió un importante papel de acompaamiento la Universidad del Externado de Bogotá, ubicada a pocas decenas de metros del barrio.

Ahora bien, para entender el entorno geocultural y las particulares circunstancias sociales que permitieron el impulso y el éxito del proyecto en el territorio es necesario proponer una breve mirada diacrónica hacia la historia social del Barrio Egipto, cuyos conflictivos matices de marginación llevaron a una condición de violencia estructural de las más brutales y radicadas en los contextos de las periferias urbanas bogotanas.

El área actualmente conocida como Barrio Egipto, construida en época colonial (1651) en territorios que habían sido asentamientos muiscas, se erige verticalmente en los cerros que delimitan la frontera oriental de Bogotá. Actualmente, forma parte de la localidad de la Candelaria, ubicada en el centro histórico de la capital colombiana. El barrio se delimita al oriente por la transversal 4 Este, al norte por la calle 12, al occidente por la carrera 3 y al sur por la calle 6. Si desde los primeros siglos de su existencia la región se ha caracterizado como barrio popular y obrero, durante la segunda mitad del siglo XX se atestigua la progresiva marginación del territorio, en particular de la zona más alejada del centro, denominada Egipto Alto y colocada entre las calles $10 \mathrm{~B}$ y 7 , la Avenida Circunvalar y la carrera 5B. 
Figura 1

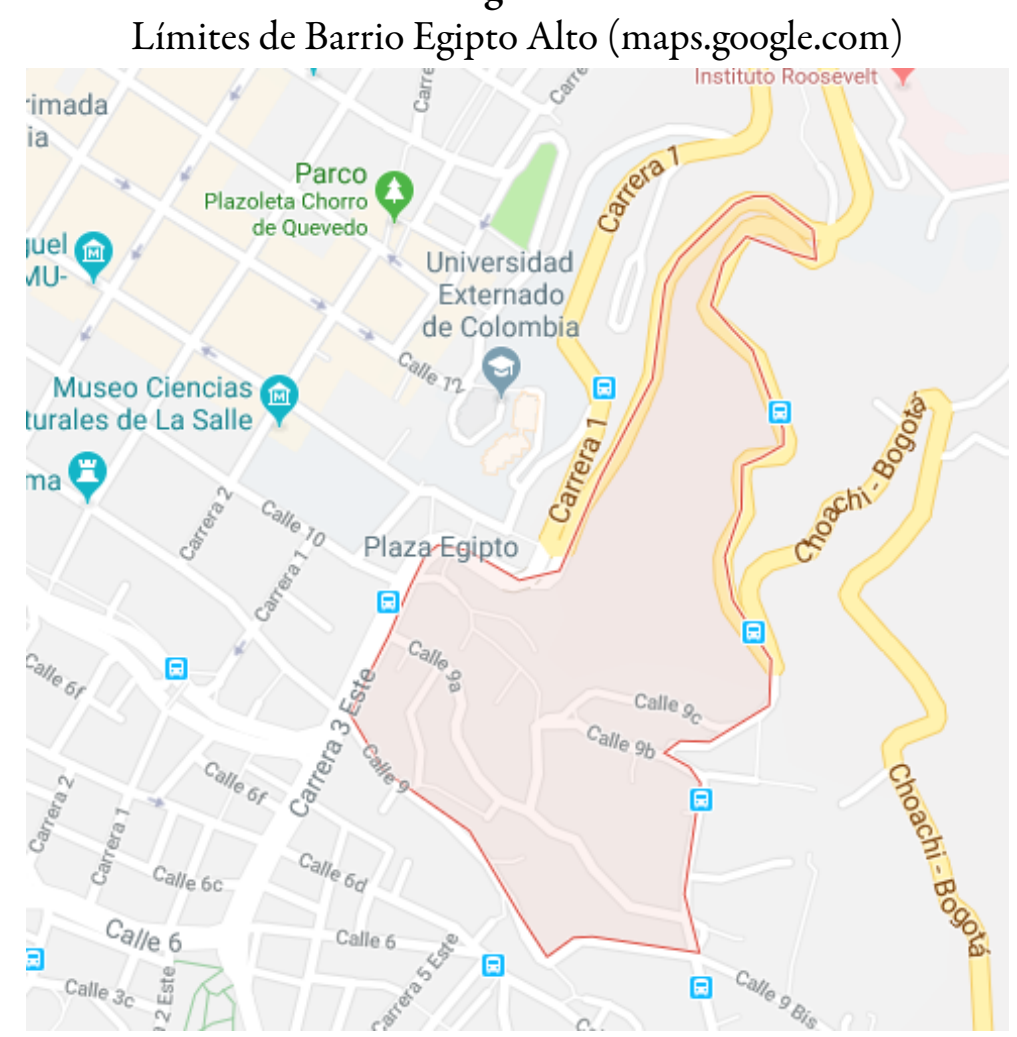

Efectivamente, ya desde principios del novecientos la falta de servicios básicos y la polarización de la pobreza se habían cristalizado como condiciones normativas, aunque parcialmente contrarrestadas por la actividad social de personajes como el padre Julio César Beltrán, quien entre 1914 y 1930 logró incentivar la instalación del primer comedor comunitario y del acueducto en algunas viviendas, y la pavimentación parcial de las calles. Sin embargo, la segregación de Egipto Alto siguió caracterizando un territorio al que hasta finales de la década de los sesenta no había llegado la electricidad, y donde las formas de re-existencia impulsadas desde los mismos habitantes del barrio no alcanzaron a contrarrestar la falta de servicios básicos y las precarias condiciones de vida de los residentes.

Desde la etapa de la historia colombiana conocida como "Época de la Violencia" (1948-1958), Egipto Alto comenzó a recibir una cantidad considerable de migrantes internos en fuga de las zonas de conflicto armado, y en particular de la región de Boyacá, dentro de un fenómeno histórico masivo por el cual el aumento poblacional en los barrios populares alcanzó niveles impresionantes: se triplicaron tanto el número de habitantes como la superficie urbana de Bogotá entre finales de los años cincuenta y comienzos de los setenta (Torres Carrillo, 2013, p. 34).

Las condiciones de extrema pobreza de la mayoría de la población local y la ausencia institucional impulsaron el desarrollo de grupos de delincuencia organizada, lo que generó una situación de extrema inseguridad y un crecimiento notable de los índices de violencia. Estas tasas aumentaron de forma vertiginosa en los primeros años ochenta, con la construcción de la Avenida de los Cerros, más conocida como Avenida Circunvalar: una infraestructura que reconfiguró la viabilidad de la zona oriental de Bogotá y la conformación del Barrio Egipto, 
profundizando la separación entre la zona alta y la zona baja, ya que la nueva avenida se construyó en un lugar histórico de mercadeo:

Al construirse la avenida por la mitad del barrio, el mercado es desplazado a la nueva plaza de mercado "Rumichaca", en el límite sur del barrio. Este hecho es un hito en la historia del barrio, ya que además de asentar las diferencias entre el bajo y el alto Egipto hizo que la actividad productiva principal se debilitara hasta el punto de desaparecer. (Yemail, Barrera, Cuarta y Díaz, 2014).

La nueva infraestructura se desarrolló a pesar de extendidas protestas sociales, que particularmente en los barrios surorientales de la ciudad estaban motivadas "en gran medida, por una previsiva resistencia a hipotéticos desalojados en caso de que el plan estatal se realizara" (Torres Carrillo, 2013). La Avenida Circunvalar llevó a una cristalización del estado de segregación de los habitantes de la zona alta de Egipto, como lo recuerda uno de los habitantes que vivieron el cambio: "la Circunvalar dividió el barrio en dos: Egipto Alto y Egipto Bajo. En Egipto Bajo tenemos universidades, colegios, panaderías, cafeterías, discotecas, hostales. En Egipto Alto no sube ni la policía" (Alex).

El abandono institucional se hizo progresivamente más evidente, lo que permitió la asunción del monopolio de la violencia en el territorio por parte de bandas criminales, que durante las siguientes tres décadas (1980-2010) se dedicarían a negocios y actividades delincuenciales: tráfico ilícito de drogas y armas, atracos y robos de carros en la Avenida Choachí, hurtos a turistas y estudiantes universitarios, extorsión a comerciantes, entre otros. A partir del año 1990, las disputas por el control territorial entre las cuatro pandillas de Egipto Alto (Décima, Novena, Parejo y Veintiuna) degeneraron en un conflicto armado de tremenda intensidad, constituido por una normalización de tiroteos y homicidios entre adolescentes, que perduraría hasta el año 2002. Jaime, líder de la iniciativa Breaking Borders y en ese entonces joven integrante de la "Banda de la Décima”, o "de Los Pilos", recuerda:

Vivimos el flagelo de las fronteras invisibles. Peleamos una guerra por casi 12 años [1990-2002], en la cual perdimos muchos familiares. [...] En mi caso perdí primos, tíos, sobrinos, papá, cinco hermanos, una hermana... Cada sector se peleaba por la venta, más que todo. Entonces quedaron estipulados los cuatro sectores que son los sitios donde más también se vendía y todo eso, pues por eso mismo comenzó ese conflicto. [...] Una cosa fue llevando a la otra, fueron matándole un amigo al otro, ese amigo tenía un hermano, ese hermano tenía un primo, y se fueron involucrando, hasta que fueron más o menos como 1300 muertos en esos doce años. La mayoría eran niños entre los 12 y 18 años, porque eran los que prácticamente resultaban comprometidos en el problema [...] Porque, por ejemplo uno no podía pasar de tal frontera pa' tal lado, o sea una calle a la otra no podía pasar, que porque era uno de la Décima, entonces no podía pasar hacia el otro sector del barrio [...] En el 1994, 1995, 1996 fueron años difíciles completamente, donde cayeron muchos muchachos, donde comenzó a haber demasiados muertos en el barrio [...] venían y mataban a uno acá, los de acá le peleaban a los de allá [...] Y así, todos los días eran dos o tres muertos lo que se veía, enfrentamientos, si no era por una frontera era por la otra, por la de abajo, con la policía, con las otras bandas. (Jaime, 2018)

El testimonio del líder de Breaking Borders da cuenta de la normatividad de la violencia en el barrio Egipto Alto, en el marco de un conflicto que, por índices de muertos y niveles de organización de los grupos armados, asumió las matrices de una guerra barrial. Ahora bien, la mayoría de los integrantes de las 
pandillas que sobrevivieron a la década de los noventa terminaron aprisionados. Paradójicamente, en un espacio heterotópico y represivo como el ambiente carcelario surgieron las semillas de la iniciativa Breaking Borders, organizada y gestionada por exmiembros de la banda "La Décima", la cual mantenía el monopolio de la violencia en la Calle 10 de Egipto Alto. Durante sus últimos períodos de detención en la cárcel "La Esperanza” de Guaduas (Cundinamarca), en el año 2015, Jaime conoció la experiencia del turismo urbano impulsada en la Comuna 13 de Medellín:

\footnotetext{
Había escuchado lo que estaba pasando en Medellín, en la comuna 13, [...] esto en Guaduas, esto en la Pola de Guaduas, esto era en un patio de paisas [...] escuché la idea esa que hacían toures, yo dije no pues... y que a ellos les toca es transportarse en un bus de un lado a otro, en cambio yo los tengo, es aquí a dos cuadras, tres cuadras [...] entonces dije no, hay que probar, comencé a tocar puertas, y sí, se ha venido el proyecto. El primero en apoyarnos fue el profesor Manuel Rojas, es el papá del proyecto. (Jaime, 2018)
}

A partir del modelo de la Comuna 13, surge en el año 2016 el proyecto Breaking Borders, liderado por Jaime, con el aporte fundamental del profesor Manuel Rojas Neira de la Universidad Externado de Colombia, quien apoyó los procesos de organización estructural, el aprendizaje de nociones para transmitir a los visitantes, la capacitación laboral y la difusión de la iniciativa en algunas redes de turismo urbano. Cabe resaltar que, como lo testimonian los mismos integrantes de Breaking Borders, el proyecto logró una aceptación inicial en la comunidad barrial gracias a la "autoridad" de los exintegrantes de la pandilla "La Décima”, Jaime y Andrés (segundo coordinador del proyecto), en el tejido social de la Calle 10 de Egipto Alto. Este primer elemento nos da cuenta del impulso autónomo del proceso de re-existencia a partir del aprovechamiento y de la reversión simbólica de las jerarquías sociales generadas en los años de la guerra barrial.

\section{Arte visual y memorias orales: la experiencia de las narraciones "desde adentro"}

A partir de su surgimiento, y a lo largo de los siguientes cuatro años, la iniciativa Breaking Borders logra consolidarse tanto en términos de incremento de los visitantes como en su capacidad de involucrar a los habitantes de la Calle 10 de Egipto Alto en el papel de guías turísticos: de un lado, los exintegrantes de la pandilla "La Décima" que terminan de descontar sus condenas en los penitenciarios, al regresar a su barrio, se encuentran con la posibilidad de asociarse al proyecto en tanto colaboradores; de otro lado, las y los adolescentes de la generación nacida después del fin del conflicto interbarrial encuentran en Breaking Borders una oportunidad de capacitación laboral y de alternativa concreta a la falta de posibilidades que caracteriza las geografías violentadas de los cerros orientales de Bogotá. Según todos los testimonios recogidos, tanto de miembros del proyecto como de habitantes del sector, la inserción de la iniciativa en el contexto de las vivencias cotidianas del barrio ha propiciado una reducción exponencial de los índices de violencias y de los atracos a extranjeros y estudiantes en el sector, además de abrir nuevas oportunidades de trabajo. 
En esta sección, a partir de la noción de re-existencia presentada en el aparato introductorio, se procurará señalar los caracteres centrales en la construcción de una narración autónoma y autorrepresentativa dirigida a los turistas, en el intento de destacar unos primeros factores constitutivos de un modelo cultural de referencia continental en el marco del turismo comunitario de las periferias urbanas.

El proyecto pensado y realizado por Breaking Borders consta de un tour de alrededor de dos horas en el cual varios miembros de la comunidad presentan la historia de Bogotá y de Egipto Alto, comenzando por la huella cultural de las poblaciones muiscas que poblaban el territorio anteriormente a la conquista de Colombia. El recorrido tiene comienzo en la plazoleta del Chorro de Quevedo, lugar fundacional en la historia colonial bogotana; de ahí, los turistas son acompañados a Egipto Alto, cruzando la Iglesia de Nuestra Señora de Egipto, puerta de acceso al barrio, hasta llegar a la zona de invasión conocida como sector de San Bruno.

A lo largo del camino, los guías exponen algunos momentos cruciales de la historia contemporánea de la capital colombiana, desde el Bogotazo hasta los fenómenos de desplazamiento forzado, para trazar un contexto de las condiciones de marginación y olvido institucional de Egipto Alto previas a la generación del conflicto interno. Sucesivamente, los miembros de Breaking Borders proponen narraciones individualizadas de las experiencias propias en relación con la época más violenta de la historia barrial: la década de los noventa. Finalmente, los relatos orales se enfocan en el enorme proceso de transformación impulsado en el territorio por medio de la iniciativa.

Ahora bien, es posible identificar dos vectores dominantes en la experiencia de turismo comunitario urbano propuesta por Breaking Borders. De un lado, el arte visual: los murales que acompañan las narraciones son alrededor de treinta, cada uno de los cuales simboliza episodios históricos, figuras míticas y personajes memorables de la memoria local, así como representaciones artísticas de la condición de marginación, violencia y transformación. De otro lado, la performance oral: las memorias asociadas a la historia del territorio se acompañan de una profunda implicación emotiva por parte de los narradores, así sean testigos directos o "hijos" de la generación del conflicto. 
Los murales: el arte de la re-existencia

Figura 2

Mural en representación de "Beto" (foto del autor)

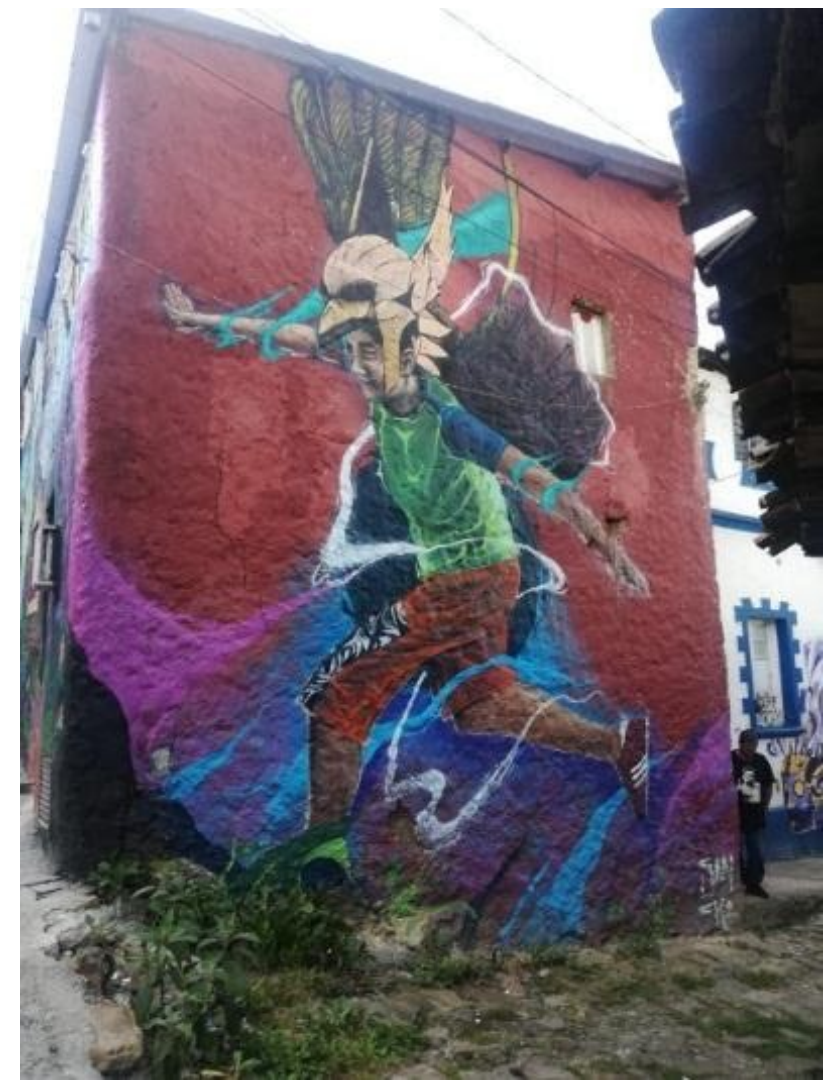

El arte visual es componente determinante de los relatos propuestos a los turistas. Las decenas de murales que constelan el barrio, realizados parcialmente por residentes de la Calle $10 \mathrm{y}$, en su mayoría, por artistas nacionales y extranjeros que han ofrecido su aporte voluntario, actúan bajo diferentes planes de acción de re-existencia. Si algunas obras son fruto de una expresión artística de la condición de segregación sufrida por los barrios marginales de la ciudad, otras celebran la necesidad de pensar la relación de los habitantes con el territorio a partir de perspectivas solidarias, ecológicas y colaborativas.

La amplia red de evocaciones de las figuras pintadas en las paredes externas de las casas del barrio se conforma también con matices biográficos de personajes emblemáticos de la historia local, en imágenes caracterizadas por un profundo valor simbólico arraigado a la memoria colectiva. Este tipo de murales entra con contundencia en la producción de una narración autónoma y eficaz, al representar algunos de los episodios más significativos de la época del conflicto interno. Es el caso del mural de la Figura 2, en el que se representa a Beto, niño de 12 años asesinado en una cancha de fútbol a principios de los años noventa, con el comienzo del conflicto interno entre las cuatro pandillas que se disputaban el monopolio de la violencia y de los tráficos ilícitos en el territorio.

La imagen de Beto evoca las más siniestras crueldades que caracterizaban los enfrentamientos entre pandillas: su asesinato se debió al simple hecho de "pertenecer" a una familia enemiga. Su individualización, si bien en 
representación de una historia colectiva y comunitaria, permite de-normalizar las praxis de muerte y los caracteres de la venganza interfamiliar que hasta hace pocos años caracterizaban las geografías violentadas de Barrio Egipto Alto. En este marco, cabe resaltar que las unidades de arte visual que integran el recorrido mantienen un valor performativo que transciende el simple contacto con los turistas. Los murales, en tanto figuraciones colocadas en un espacio público, negocian sus significados con el entorno social, posicionándose en un proceso de diálogo diario con el territorio circunstante y con las personas que transitan por ese espacio: no sólo los visitantes, sino también los habitantes del barrio.

Los dos niveles de destinatarios propios de los murales urbanos (Blasco, 2015, p. 305) posibilitan, en el caso del mural de Beto, la elaboración de un mensaje de responsabilización comunitaria, en un proceso de reviviscencia cotidiana, viva y conmovedora, de las consecuencias extremas del conflicto interno. De otro lado, este tipo de figuraciones suscita en el turista una concientización nítida de las formas constitutivas de estos conflictos, en el intento de desvincular las violencias urbanas de cierta tendencia a la trivialización y a la mitificación del "mundo favelesco": un proceso combinado de la noción de liminalidad, es decir, de la atracción "por lugares que representan una diferenciación de sus propios patrones culturales y sociales" (López Zapata, Mees y Gómez, 2017, p. 32), y de la connotación del espacio de la favela como territorio seductor y fascinante, debido primariamente a un extendido abanico de representaciones literarias y cinematográficas. Si bien la experiencia turística de Breaking Borders no está exenta de este tipo de procesos, los murales actúan en una dirección de desmitificación de los modelos violentos vinculados con la presencia de pandillas en el territorio.

Figura 3

Mural en representación de Celina (impulsetravel.co)

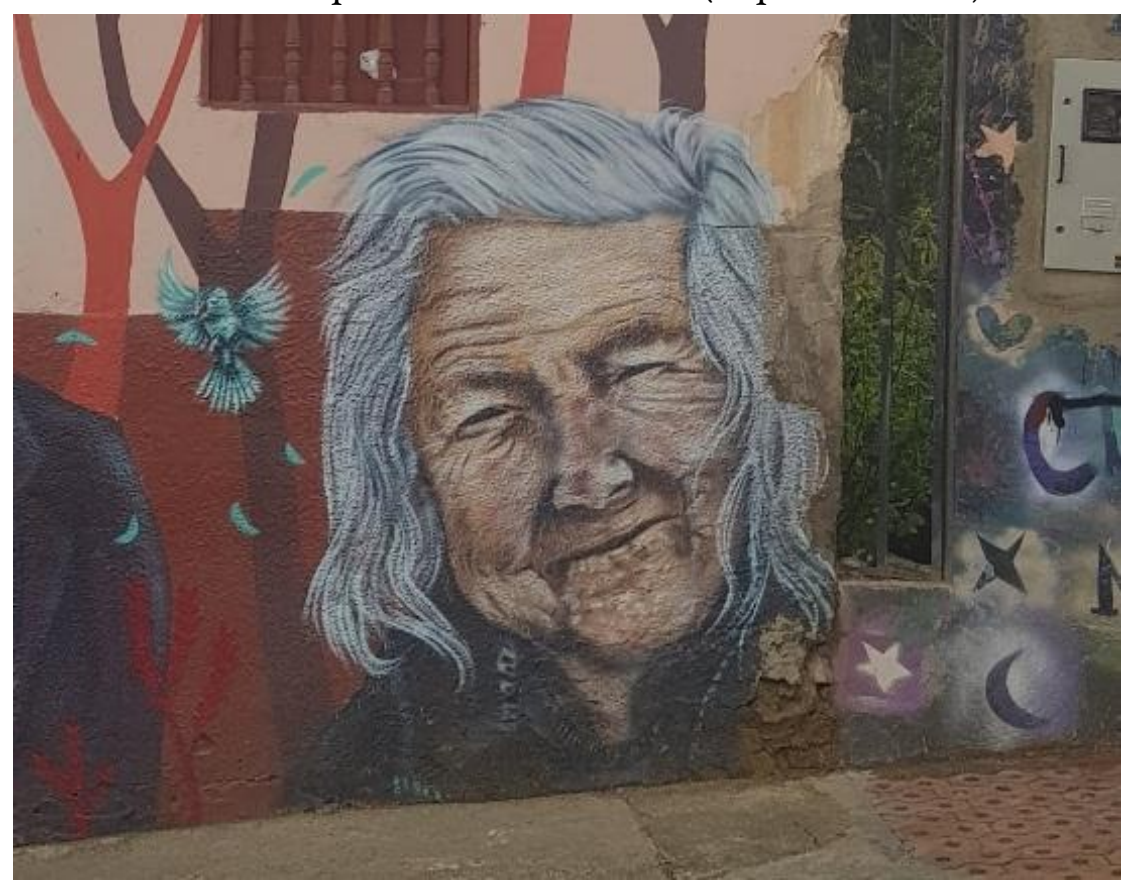

En este marco, el arte visual asume en la experiencia turística un papel de quebrantamiento de los imaginarios de fascinación vinculados con el espacio 
periférico urbano. De ahí que los murales no se limitan a la representación de acontecimientos violentos, sino que también se ocupan de configurar memorias y derroteros de re-existencia. Es el caso de la pintura de la Figura 3, en la cual aparece un retrato de Celina, habitante de la zona de invasión San Bruno de Egipto Alto. Como lo recuerda Jaime, en la época más dura del conflicto

Había mujeres que se ocupaban de cuidar a los heridos, como Celina, abuelita Celina, [...] porque acá no hay hospital, el hospital más cercano queda prácticamente pasando la novena, entre novena y veintiuna, obviamente le tocaba a uno cruzar dos barrios enemigos, pues, un herido, pues prácticamente lo remataban, entonces desde que el balazo no fuera tan grave iban a donde Celina y Celina le decía a uno qué es [...] le cuidaba a uno las heridas y todo, más que todo con plantas medicinales como la Solda con Solda, el Saúco, y varias plantas que utilizaban así... Además, le sacaba a uno las balas, sin anestesia (Jaime, 2018)

A partir de su papel sustitutivo de la asistencia hospitalaria durante los enfrentamientos entre pandillas, Celina se convierte a lo largo de los años en ícono de re-existencia. De personaje simbólico de los procesos de reconformación autónoma de la autogestión comunitaria de la salud, la figura de Celina se convierte progresivamente, en la memoria colectiva del barrio, en el contrapeso de la experiencia brutal del conflicto. Ante las geografías violentadas, representadas por Beto, la figura de Celina simboliza la re-existencia de la vida comunitaria frente a la condición normalizada de la muerte violenta.

La individuación de figuras icónicas de la historia barrial, como Beto y Celina, posibilita un relato vivo y repleto de patrones testimoniales e históricos dirigido a los visitantes. Al mismo tiempo, este proceso interviene en tanto factor de negociaciones simbólicas dentro de la comunidad barrial, en el marco de nuevas trayectorias de pensar el territorio y pensarse en ello, impulsadas a partir de un proceso colectivo de re-existencia. La posibilitad, por los turistas, de conocer a doña Celina, quien sigue viviendo en el barrio y suele compartir con los visitantes algunos episodios de su actividad de enfermera casera a lo largo del conflicto, permite entretejer la memoria pintada con la memoria oral, el segundo pilar de la experiencia de turismo comunitario de Breaking Borders.

\section{Memorias orales e inclusividad}

Se ha argumentado sobre la relevancia del arte visual en tanto producto artístico dialógico, con un papel operativo en la activación de procesos de memoria colectiva y de re-existencia. Paralelamente, la historia de violencias y transformaciones del Barrio Egipto Alto se enuncia por medio de las narraciones orales de los guías, que entretejen nociones históricas aprendidas y memorias propias evocadas. No es objetivo de este artículo analizar las metodologías expositivas y las técnicas conversacionales utilizadas en las performances orales de los guías ante los turistas. Sin embargo, en un proceso de acercamiento a los rasgos de re-existencia laboral y cultural del proyecto, cabe resaltar algunos elementos clave en la caracterización constitutiva de los relatos expuestos a los visitantes de Egipto Alto.

Cada tour contempla la presencia de un grupo de guías que, según las necesidades y las disponibilidades, se integra de un número variable entre 2 y 10 personas. Las narraciones de los diferentes miembros del proyecto se componen 
de un "guion" común, en el que se trazan algunos pasajes de la historia de la ciudad y de la fundación del barrio, y la descripción de los murales y de ciertos lugares simbólicamente densos en la época del conflicto interno. Estas exposiciones se caracterizan por cierta dinamicidad, pues diariamente son integradas con consideraciones tanto endógenas como exógenas. Es común, a modo de ejemplo, la inserción en la narración de comentarios realizados por turistas acerca de un determinado mural, lo que modifica el guion básico de los relatos orales.

Estos elementos se combinan con memorias más personales, que varían de guía en guía, y que es posible catalogar en dos grupos enunciadores: las voces de los testigos directos, es decir, de las personas que vivieron en primera persona el conflicto, y las voces de las generaciones sucesivas, que se apropiaron de los relatos de sus familiares para exponerlos a partir de su lugar enunciativo de "hijos" de la violencia. Esta dinámica polifónica permite la construcción de una red de memorias al mismo tiempo individuales y colectivas, que produce una narración de alta eficacia emotiva, en un heterogéneo tejido de voces multíplices en constante interacción.

En dicho proceso dinámico de negociación de memorias colectivas asume un papel central el elemento de la inclusividad; es decir, de la gradual integración de nuevas voces de expresidiarios y jóvenes del barrio en las narraciones orales dirigidas a los turistas. En este marco, primariamente, la inclusividad resulta determinante en el círculo virtuoso impulsado por el proyecto Breaking Borders en términos laborales. Con la progresiva difusión de la iniciativa, se facilita por parte de los líderes la introducción de nuevos guías, quienes proponen a lo largo del tour otras perspectivas subjetivas acerca de la violencia y de la transformación. Es el caso de Alex, quien, al terminar de descontar su condena en 2017, se encontró frente a la posibilidad de participar en el proyecto:

Cuando salí de la cárcel me encontré este proyecto. Yo salía con la otra mentalidad: yo tengo mi familia y tengo mi esposa, ¿y qué? ¿Yo me voy a dejar morir? Me tocaba ir a robar y a hacer el hijueputa porque no puedo hacer más. Pero cuando me vi a Andresito, que fue uno de los fundadores [...] Cuando salí me ofreció esto, y listo, se lo recibí. Pero hoy me siento orgulloso de estar en el proyecto porque yo estaba saliendo a robar otra vez, y cuando me dijeron Jaime y el Pato: venga, tenemos un proyecto así, mi hermano, no vamos a ganar mucho pero bueno y tal... Usted sabe que la tranquilidad nunca se compra con dinero. Hermano, nos robamos harto y disfrutamos, hoy en día vivimos con un agua panela y un pan con nuestra familia, pero relajados. (Alex, 2018)

Asimismo, Memo, hermano del fundador Jaime e integrante del proyecto, testimonia cómo Breaking Borders funcionó de mecanismo de re-existencia, para reintegrarse en la comunidad barrial desde una perspectiva diferente de las dinámicas sombrías de una geografía violentada:

Yo el proyecto lo conocí hace un año [octubre de 2017] porque [...] yo estaba condenado a 65 años de cárcel y duré 23 años, me hicieron una rebaja de pena [...] ya llevaba mucho tiempo en la cárcel. Salí y me proyecté con Jaime en este sistema, el hermano me comentó como eran las cosas y pues ahí vamos, mi hermano colaborándole al chino y a mis demás compañeros para sacar los niños adelante. El barrio, el Externado de Colombia... Mucha gente nos está apoyando [...] Son cosas que han pasado y que seguirán cambiando, queremos cambiar nuestro estigma que hay ahorita. Vamos a colaborar con los muchachos y vamos a salir adelante (Memo, 2018) 
Las palabras de Alex y Memo dan cuenta de la solidez de la red laboral intracomunitaria constituida en la Calle 10 del Barrio Egipto Alto, conformada en modalidad de cadena social autónoma y solidaria. De un lado, la contribución de Alex y Memo al proyecto permite la integración de un nuevo testigo directo, lo que implica una mejoría de la red de voces narrativas propias; de otro, la presencia estructurada de Breaking Borders en el territorio le permitió a Alex una oportunidad laboral inmediata, autónoma y comunitaria. De ahí que los procesos de construcción cultural de memorias y de posibilitación de oportunidades laborales avancen de forma mutua y recíproca.

La inclusividad resulta, en este sentido, elemento central para el crecimiento del proyecto de re-existencia de Breaking Borders. Si bien es necesario considerar los límites numéricos en las posibilidades de integración -el mercado turístico no es tan amplio como para involucrar a cada uno de los habitantes de la calle 10 , ni es pensable que una comunidad entera comparta las mismas ambiciones-, la multiplicidad de voces consiente una desvinculación de la identificación del proyecto con la unicidad de una persona, imponiéndose más bien como iniciativa de transformación comunitaria gestionada en modalidad colectiva. Este aspecto resulta central también en los objetivos pedagógicos fijados por el proyecto; es decir, en la acción de ofrecer y exponer diariamente a los jóvenes residentes del barrio una solución laboral autónoma. Actualmente, alrededor de una decena de adolescentes están involucradas e involucrados en el proyecto. Tal y como lo señala Ángel, habitante del sector:

Breaking Borders ha ayudado a apartarnos harto de la violencia, de la guerra, y hemos estado más juntos, enseñándoles a los muchachos de hoy en día que no estén como nosotros, que nos tocó pasar hambre, guerra, cuidarnos sin los padres... Entonces para que ellos no sigan el camino de nosotros, para que ellos abran los ojos, y se metan a ver que en Breaking Borders hay mucho que hacer, hay muchas artes y posibilidades. Si la quieren coger por lo bien, les va bien... y si no, pobrecitos, les va a costar duro no haber aprendido lo que nosotros les estamos enseñando. (Ángel, 2018)

En conclusión, la experiencia de turismo comunitario en la Calle 10 del Barrio Egipto Alto se constituye con una textura entre arte visual, exposiciones orales de la historia bogotana y memorias testimoniales. Estos patrones permiten elaborar una vivencia de re-existencia pensada y gestionada "desde adentro", si bien con el acompañamiento inicial de la Universidad del Externado. El proceso se concreta en transformaciones diarias de las geografías violentadas, tanto en términos de concientización cultural y de reducción de los índices de violencia, como en la producción de posibilidades autónomas de trabajo para los habitantes del barrio: en trayectorias directamente vinculadas con el proyecto Breaking Borders, en la Calle 10 de Egipto Alto se están desarrollando actividades de venta al detalle de artesanías y de talleres de madera.

Con el aporte de las entrevistas realizadas a algunos integrantes del proyecto, se han identificado los rasgos centrales en la construcción de un modelo de turismo comunitario propio: la intervención por medio del arte visual en el territorio, la iconización de personajes de re-existencia y la inclusividad en la construcción de memorias orales. Estos elementos han permitido la conformación autónoma de la iniciativa Breaking Borders en tanto modelo de alta atractividad turística y forma activa de emancipación comunitaria en un espacio oprimido por las dinámicas excluyentes de las geografías violentadas. 


\section{Consideraciones conclusivas: posibilidades de exportación y problematizaciones del modelo bogotano}

A lo largo del artículo se ha intentado trazar los rasgos caracterizadores del proceso de re-existencia cultural y laboral vinculados con el proyecto de turismo comunitario urbano Breaking Borders, organizado y gestionado por algunos miembros de la Calle 10 de Barrio Egipto Alto de Bogotá. El proceso de transformación social logrado por medio de la iniciativa plantea la necesidad de una reflexión desde las ciencias sociales acerca de las posibilidades de exportación del modelo de turismo comunitario bogotano.

A pesar de los elementos señalados en la sección anterior sobre las modalidades de producción de las narraciones propuestas a lo largo de los tours, cabe resaltar que los logros obtenidos en la difusión del proyecto y en su aceptación en el territorio no pueden limitarse a factores de impulso social y cultural endógenos. En este marco, es posible identificar elementos contextuales y externos que concurrieron al fortalecimiento de Breaking Borders.

Entre ellos, el particular posicionamiento geográfico del Barrio Egipto en el espacio urbano de Bogotá permite una cercanía a los centros económicos y turísticos de la Candelaria que facilita las conexiones infraestructurales y los procesos de comunicación entre el proyecto y los flujos de extranjeros. Asimismo, el impulso cultural y la capacitación laboral ofrecidos por la Universidad del Externado, ubicada a pocos metros de la entrada al barrio, han sido determinantes para garantizar las herramientas necesarias en la elaboración de una narración autónoma y en el aprendizaje de nociones comerciales y relacionales útiles para fortalecer el contacto con los turistas.

De ahí que es necesario considerar que la hipotética exportación del modelo de la Calle 10 de Barrio Egipto difícilmente podría funcionar con la misma eficacia en zonas menos alcanzables de la ciudad de Bogotá y de otras metrópolis latinoamericanas, en donde posiblemente sería necesario apuntar a formas más institucionalizadas de turismo urbano, como en los casos de la Comuna 13 y de algunas favelas de Río de Janeiro. De otro lado, sería complejo imaginar el turismo comunitario como sistema estructural de diferentes periferias urbanas de una misma ciudad, con el riesgo de generación de competencias y de debilitación de los patrones autónomos del proyecto.

Finalmente, un último elemento funcional a la activación de la iniciativa de Breaking Borders ha sido el reconocimiento social de los exmiembros de la pandilla, en un territorio donde los grupos armados se identificaban de facto como figuras de autoridad en las jerarquías relacionales comunitarias. Un factor problemático como la imposición del control territorial por medio de la acción violenta ha sido convertido en un medio preferencial para alcanzar la confianza comunitaria en el impulso al proyecto. Si bien dicha circunstancia no es imprescindible para la propulsión de este tipo de actividades, no es de infravalorar la tracción social de una estimulación endógena y profundamente radicada en las estructuras del tejido comunitario local.

A raíz de condiciones de marginación social y exclusión cultural comparables, y al considerar las peculiaridades contextuales y el conjunto de factores señalados, se dejan abiertas las siguientes preguntas. ¿Es la iniciativa de la Calle 10 de Barrio Egipto Alto exportable a otros espacios periféricos urbanos del 
continente? ¿De qué forma sería posible replicar los patrones de autonomía y reexistencia del proyecto de turismo comunitario Breaking Borders? Alrededor de estas preguntas investigativas pueden desarrollarse reflexiones desde las ciencias sociales y humanas que aborden, en una mirada continental, las posibilidades y las problematizaciones en la aplicación a otros contextos del modelo de Egipto Alto.

\section{Referencias}

Álvarez, G. H. (2005). Gran Buenos Aires, conurbano y partido de San Martín: exclusión social y segregación urbana. Scripta Nova, IX (194), 52 pp. Recuperado de: http://www.ub.edu/geocrit/sn/sn-194-52.htm

Alves, J. A. (2011). Topografias da violência: necropoder e governamentalidade espacial em São Paulo. Revista do Departamento de Geografia, 22, 108-134.

Bello Ramírez, J. A. y Parra Gallego, G. (2016). Cárceles de la muerte: necropolítica y sistema carcelario en Colombia. Universitas humanistica, 82, 365-391.

Blasco, L. M. (2015). Gubernamentalidad neoliberal, muralismo y resistencia política en el barrio de La Boca. Question, 1(48), 298-307.

Casas Jurado, A. C., Soler Domingo, A. y Pastor, V. J (2012). El turismo comunitario como instrumento de erradicación de la pobreza: potencialidades para su desarrollo en Cuzco (Perú). Cuadernos de Turismo, 30, 91-108.

Fanon, F. (1963). Los condenados de la tierra. México: FCE.

Frisch, T. (2012). Glimpses of another world: The favela as a tourist attraction.Tourism Geographies, 14(2), 320-338.

Gonçalves de Lima, I. (2005). La ciudad compleja: entre el miedo dirigido y las reexistencias. En O. Gutiérrez (Coord.), La ciudad y el miedo (pp. 83-86) VII Coloquio de Geografía Urbana, Girona: Universitat de Girona.

Gruber Sansolo, D. (2003). Turismo e sustentabilidade na Amazônia: um novo conteúdo territorial e a experiência no Município de Silves. Pasos: Revista de Turismo y Patrimonio Cultural, 1(1), 39-50.

Harvey, D. (2003). Espacios de esperanza. Madrid: Akal.

Janoschka, M. y J. Sequera (2014): Procesos de gentrificación y desplazamiento en América Latina, una perspectiva comparativista. En J. J. Michelini (Ed.), Desafios metropolitanos. Un diálogo entre Europa y América Latina (pp. 82-104), Madrid: Catarata..

Jaramillo Marín, J., Parrado Pardo, E. y Louidor, W. (2019). Geografías violentadas y experiencias de reexistencia. El caso de Buenaventura, Colombia, 2005-2015. Íconos, 64 (23).

Kessler, G. (2012). Las consecuencias de la estigmatización territorial. Reflexiones a partir de un caso particular. Espacios en blanco, 22, 165-198. Recuperado de http: //www.memoria.fahce.unlp.edu.ar/art_revistas/pr.10649/pr.10649.pdf

López Zapata, L., Mees, L. A. y Gómez, J. S. (2017). Turismo en territorios informales. Las motivaciones del turista para visitar las favelas de Rio de Janeiro (Brasil) y las Comunas de alta ladera en Medellín (Colombia). Conpeht, 1(1), 29-35.

López-Guzmán Guzmán T. J. y Sánchez Cañizares, S. M. (2009). Turismo comunitario y generación de riqueza en países en vías de desarrollo. Un estudio del caso en El Salvador. REVESCO. Revista de Estudios Cooperativos, 99, 85-103.

Machado, D. S. (2007). Turismo de favela e desenvolvimento sustentável: um estudo do turismo de favela no bairro de Vila Canoa, zona sul do Rio de Janeiro. Dissertação 
(Mestrado em Serviço Social). Pontifícia Universidade do Rio de Janeiro, Río de Janeiro, Brasil. DOI: .

Maldonado, C. (2005). Pautas metodológicas para el análisis de experiencias de turismo comunitario. Ginebra: OIT.

Mbembe, A. (2011). Necropolitica. España: Melusina.

Murphy, P. E. (1985). Tourism: A community approach. Londres: Methuen.

Orgaz Agüera, F. (2013). El turismo comunitario como herramienta para el desarrollo sostenible de destinos subdesarrollados. Nómadas: Critical Journal of Social and Juridical Sciences, 38, 79-91.

Parker, C. y Moreno, P. (2015). Turismo indígena urbano, ¿innovación identitaria? Atenea, 512, 231-246.

Pérez Zamorano, A. (2010). Marginación urbana. El caso del oriente mexiquense. México: Universidad Autónoma Chapingo, Centro Mexicano de Estudios Económicos y Sociales Miguel Ángel Porrúa.

Rodrigues da Silva, D. et al. (2014). Turismo Comunitario en Favelas. Un estudio del Favela Inn Hostel, Chapéu Mangueira - Rio de Janeiro, Brasil. Estudios y Perspectivas en Turismo, 23(4) 786-804.

Ruiz, E. et al. (2008). Turismo comunitario en Ecuador. Comprendiendo el community-based tourism desde la comunidad. Pasos. Revista de Turismo y Patrimonio cultural, 6(3), 399-418.

Saraví, G. (2008). Mundos aislados: segregación urbana y desigualdad en la ciudad de México. Revista Eure, XXXIV(103), 93-110.

Scott, J. (1990). Los dominados y el arte de la resistencia. Discursos ocultos. New Haven y Londres: Yale University.

Segura, R. (2014). El espacio urbano y la (re)producción de desigualdades sociales. Desacoples entre distribución del ingreso y patrones de urbanización en ciudades latinoamericanas. desiguALdades.net. Working Paper, 65, 1-31.

Torres Carrillo, A. (2013). La ciudad en la sombra. Barrios y luchas populares en Bogotá 1950-1977. Bogotá: Universidad Piloto de Colombia.

Torres Tovar, C. A. y Rincón García, J. J. (2011). Suelo urbano y vivienda social en Bogotá: la primacia del mercado y el sacrificio del interés general, 1990-2010. Bogotá: Universidad Nacional de Colombia.

Trejos, B. y Matarrita-Cascante, D. (2010). Theoretical Approximations to Community-Based Tourism: Case Studies from Costa Rica. Review of Tourism Research, 8(6), 157-178.

Yemail, A., Barrera, D., Cuartas, F. y Díaz, L. (2014). Atlas del paisaje Barrio Egipto. Bogotá: Proyecto artesano.

\section{Fuentes:}

Testimonios de los miembros de Breaking Borders y de otros habitantes de la Calle 10 de Barrio Egipto Alto (2018): Alex, Gonzalo, Jaime, Memo, Ángel, Jan, Andrés. 